\title{
The ABCs of challenges, education, and professional development
}

\section{Nicola Oberbeckmann-Winter ${ }^{1}$}

Published online: 17 June 2019

(C) Springer-Verlag GmbH Germany, part of Springer Nature 2019

A unique feature of $A B C$ is the journal's two columns, the Analytical Challenge and ABCs of Education and Professional Development in Analytical Science. This editorial introduces the columns and $A B C$ 's column editors to you-being readers, friends of scientific quizzes, teachers, students, or future authors. Read on and get to know them better.

\section{Analytical Challenge}

While the first Analytical Challenge was already published in 2003, the column fully developed into its unique diversity under the guidance of Juris Meija who became the column editor in 2009. This is Juris' view on the scope of the column:

We live in the ever-accelerating world accustomed to getting instant answers from Google. In contrast to this, the Analytical Challenge series invites us to pause and think about some analytical problem using the old fashioned paper and pencil method. This column is not here to teach analytical chemistry but to offer glimpses of fundamental problems worth pondering over. Over the last decade the column has featured a rich variety of chemical problems often with touch of cultural relevance. Why does garlic turn blue when left in vinegar, why did Avogadro's constant suddenly jump in its value during the cold war, and could Cleopatra really have dissolved her pearls to win her bet against Marc Antony? In addition, this column also features 'serious' problems with deeprooted links to fundamental analytical chemistry.

Nicola Oberbeckmann-Winter

nicola.oberbeckmann-winter@ springer.com

1 Analytical and Bioanalytical Chemistry, Springer, Tiergartenstrasse 17, 69121 Heidelberg, Germany
There is a variety of examples exploring the value of modern NMR techniques, problems exploring the various quantitation methods in analytical chemistry (standard additions, isotope dilution), or aspects of seemingly simple dilution of samples. We invite the readers not to be shy and spend some time pondering these problems or propose one from your own collection of interesting problems!

Column editor Juris Meija is a research officer at the National Research Council Canada working in the area of chemical metrology and certified reference material development (Fig. 1). His expertise lies in theoretical analytical chemistry, isotope ratio measurements, and data analysis. Since 2014, he has served as the Chair of the IUPAC Commission on Isotopic Abundances and Atomic Weights and is also a IUPAC delegate to the Joint Committee for Guides in Metrology, Working Group 1: Guide to the Expression of Uncertainty in Measurement (GUM). He is a column editor and member of the International Advisory Board of Analytical and Bioanalytical Chemistry, and has been actively involved in many recent international activities such as the redefinition of the mole, naming of the new chemical elements, and revisions of the GUM.

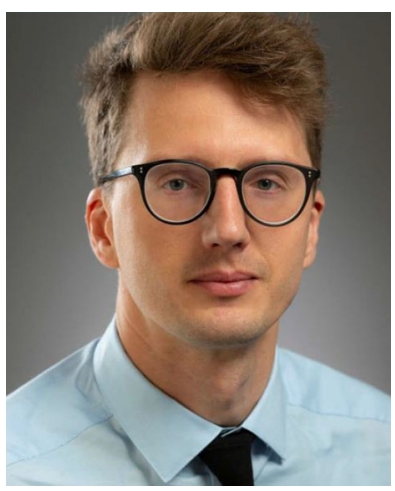

Fig. 1 Juris Meija 


\section{ABCs of Education and Professional Development in Analytical Science}

Although ABCs of Education and Professional Development in Analytical Science may appear to be a newer column, starting in 2013, it was founded by the former column editors John Fetzer, Reiner Salzer, and Tom Wenzel when the two predecessor columns "ABCs of Teaching Analytical Science" and "Building a Professional Career" were merged to reflect the necessity to develop in students the professional skills they will need for success in their careers. In 2018, Martin Vogel joined the team of column editors, replacing Reiner Salzer who decided to retire after many successful years.

Some articles in this column are solicited by the editors when they learn of ongoing activities that they believe will be of interest to the readership of ABC. Unsolicited submissions are also welcomed but will, like all submissions, undergo peer review prior to a decision on publication. In an effort to help the community better understand the scope of articles desired for this column, the editors have crafted the following statement:

ABCs of Education and Professional Development in Analytical Science is a forum for articles that describe educational innovations or activities designed to advance the professional development of analytical and bioanalytical chemists or that help people better manage their careers and build the skills to thrive in their careers. Articles may describe classroom and laboratory experiences or pedagogies that enhance learning outcomes and the professional development of undergraduate and/or graduate students. Articles describing innovative departmental or system-wide approaches to the teaching of analytical chemistry or preparation of students for careers in analytical or bioanalytical chemistry are appropriate. Opinion pieces on aspects of education and professional development are welcomed. Submission of manuscripts is similar to the process for research

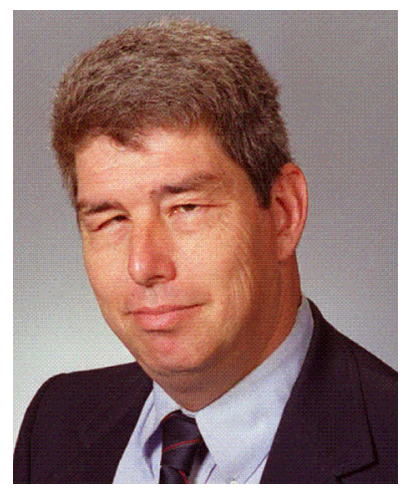

Fig. 2 John C. Fetzer

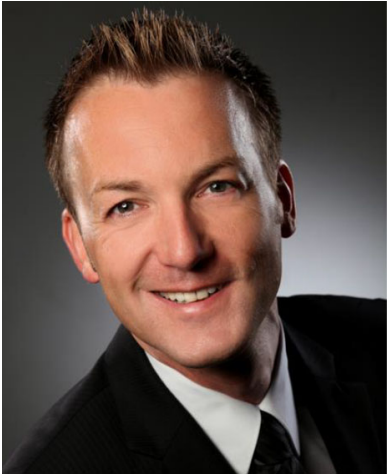

Fig. 3 Martin Vogel

manuscripts. Decisions on publication involve a peerreview process.

We believe that ABCs of Education and Professional Development in Analytical Science has been an outstanding forum for the dissemination and discussion of educational topics and professional development among analytical and bioanalytical chemists. We look forward to our role in continuing this important component of $A B C$.

Column editor John C. Fetzer worked for a major petroleum company for over two decades before founding his own consulting company (Fig. 2). He has served on the editorial advisory boards of Analytical Chemistry, the Journal of Chromatography, Analytical and Bioanalytical Chemistry (Springer-Verlag), and Polycyclic Aromatic Compounds.

He has over 100 peer-reviewed research publications in areas of chromatography and molecular spectroscopy of the polycyclic aromatic hydrocarbons and petroleum-related materials. He also has written numerous book chapters and authored the books The Chemistry and Analysis of the Large Polycyclic Aromatic Hydrocarbons, J. C. Fetzer, John Wiley and Sons, New York, p. 1-288 (2000) and Career Management for Chemists, Springer-Verlag, Berlin, p. 1266 (2004). He founded and wrote over 50 articles for the column "Building a Professional Career."

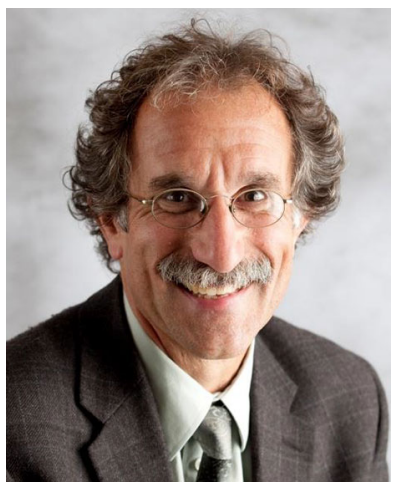

Fig. 4 Thomas J. Wenzel 
Column editor Martin Vogel received his $\mathrm{PhD}$ in analytical chemistry from the University of Münster in 2001 (Fig. 3). Following his doctoral studies, he joined the faculty of Chemical Technology at the University of Twente/The Netherlands as an assistant professor of analytical chemistry, and since 2006, he has been a member of the Department of Analytical Chemistry at the University of Münster, where he has been giving courses in general and inorganic chemistry for undergraduates and in analytical chemistry for graduate students. His research interests are mainly in the fields of hyphenated techniques with a focus on electrochemistry/mass spectrometry (EC/MS). From 2004 to 2015, he was a member of the board of the Division of Analytical Chemistry of the German Chemical Society (GDCh), in which he was chairman from 2012 to 2015. Currently, he is the Chairman of GDCh's Working Party Separation Science and a GDCh delegate in EuCheMS' Division of Analytical Chemistry (DAC). Additionally, together with his colleagues at the University of Münster, he is a passionate co-organizer of symposia and congresses in Münster, e.g., ISC 2008, Metallomics 2011, EWCPS 2015, and ANAKON 2019.

Column editor Thomas J. Wenzel is the Charles A. Dana Professor of Chemistry at Bates College in Lewiston, Maine (Fig. 4). He currently carries out research with the aid of undergraduate students in the area of chiral NMR shift reagents. His research accomplishments were recognized with the 2010 American Chemical Society Award for Research at an Undergraduate Institution. He is active in efforts to reform the undergraduate analytical chemistry curriculum to include inquiry- and project-based experiences. His educational activities were recognized through receipt of the 1999 J.C. Giddings Award for Excellence in Education sponsored by the Analytical Division of the American Chemical Society. More information about his activities can be found at http:// www.bates.edu/chemistry-biochemistry/faculty/thomaswenzel/.

We thank all former and current column editors for their dedication and their enthusiasm to keep these two columns as they are unique features of $A B C$ !

Publisher's note Springer Nature remains neutral with regard to jurisdictional claims in published maps and institutional affiliations.

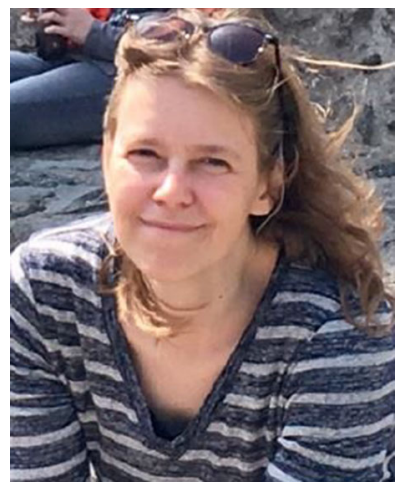

Nicola Oberbeckmann-Winter started working in publishing in 2005 and has been the Managing Editor of $A B C$ since 2013. She studied chemistry at the University of Bielefeld, Germany, including a stay at Queens University Belfast, Northern Ireland. In 2001, she received her PhD from RuhrUniversity Bochum, Germany, which was followed by a postdoctoral stay at Université Louis Pasteur, Strasbourg, France. 